\title{
Etnoenfermagem como metodologia de pesQuisa para a congruência do cuidado
}

\author{
Etnonursing as research methodology for the congruence of care \\ Etenoenfermería como metodología de pesquisa para la congruencia del cuidado
}

\begin{abstract}
Rosemary Silva da Silveira', Cleusa Rios Martins', Valéria Lerch Lunardi', Wilson Danilo Lunardi Filho'
'Fundação Universidade Federal do Rio Grande. Departamento de Enfermagem. Rio Grande, RS
\end{abstract}

Submissão: 19/09/2008

Aprovação: 14/05/2009

\section{RESUMO}

A etnoenfermagem, como metodologia de pesquisa, é utilizada para enfocar o contexto cultural e de cuidados à saúde de uma cultura específica. Com o objetivo de demonstrar o processo de aplicação desta metodologia na enfermagem, a partir do proposto por Leininger, são apresentadas Quatro fases de observação, uma de entrevista e Quatro fases de análise dos dados, contemplando critérios específicos e congruentes com o paradigma Qualitativo. Estas fases não são estanques, inter-relacionam-se de modo imbricado. Considerase que o conhecimento produzido pode contribuir tanto para os sujeitos de pesquisa, como para a prática dos trabalhadores da saúde, desenvolvendo a enfermagem como ciência e proporcionando novos caminhos para o cuidado à saúde, para o exercício da profissão, através da ética, da diversidade de trabalhadores; complementando a Teoria de Leininger.

Descritores: Enfermagem; Metodologia; Cuidado.

\section{ABSTRACT}

Etnonursing, as a research methodology, is applied to approach the cultural context and of care in health of one specific culture. Aiming at demonstrating the process of application of this methodology in nursing, from what is proposed by Leininger, four steps of observation are presented, one of interview and for steps of analysis of data, covering specific and congruent criteria with the Qualitative paradigm. These steps are not isolated, they relate to one another in an intricate way. It is considered that the knowledge produced can contribute largely for the subjects of the research as well as for the practice of the health workers, developing nursing as a science and providing new paths for the health care, for performing their jobs, through ethics, diversity of workers; complementing the theory of Leininger. Descriptors: Nursing; Methodology; Care.

\section{RESUMEN}

La etnoenfermería, como metodología de pesquisa, es utilizada para concentrar el contexto cultural y de los cuidados a la salud de una cultura específica. Con el objetivo de demostrar el proceso de aplicación de esta metodología en enfermería, partiendo de lo propuesto por Leininger, son presentadas cuatro fases de observación, una de pesquisa y cuatro fases de análisis de datos, con contemplación de criterios específicos y congruentes en el paradigma cualitativo. Estas fases no están estanques, tienen interrelación de manera imbrincada. Se considera Que el conocimiento producido puede contribuir tanto para los sujetos de la pesquisa, como para la práctica de los trabajadores de la salud, desarrollando la enfermería como ciencia y proporcionando nuevos caminos para el cuidado con la salud, para el ejercicio de la profesión, a través de la ética de la variedad de trabajadores; complementando la teoria de Leininger.

Descriptores: Enfermería; Metodologia; Cuidado. 


\section{INTRODUÇÃO}

A Teoria da Diversidade e da Universalidade do Cuidado Cultural de Leininger tem sido utilizada como referencial teórico e metodológico em estudos Qualitativos realizados pela enfermagem em diversos países. No Brasil, tem se mostrado fundamental para conhecer a cultura, crenças e valores dos usuários a serem assistidos, assim como para possibilitar a construção de conhecimentos e implementar um cuidado culturalmente congruente à realidade de pessoas de diferentes culturas ${ }^{(1)}$.

Leininger aponta alguns desafios para os pesquisadores da enfermagem transcultural nesse terceiro milênio, como o desenvolvimento de estudos para avaliar benefícios do cuidado culturalmente competente, conhecer aspectos culturais ainda pouco explorados e abordar Questões éticas, morais e legais relacionadas às diversas culturas; e a implementação de projetos colaborativos de educação, pesQuisa e prática multi e interdisciplinares, mantendo o foco distinto de cada disciplina ${ }^{(2)}$.

Dentre as abordagens da pesquisa Qualitativa utilizadas na enfermagem e no campo da saúde para obter dados relacionados à cultura de um grupo e ao modo como os profissionais de saúde exercem sua autonomia no cotidiano do trabalho, destacam-se a etnografia e a etnoenfermagem proposta por Leininger: "Estes métodos são formas poderosas de obter fatos, sentimentos, visões de mundo e outros tipos de dados Que revelam o mundo real, verdades e modos de vida das pessoas", permitindo a compreensão de crenças e valores ${ }^{(3)}$.

O conhecimento desenvolvido tanto na etnografia como na etnoenfermagem envolve duas perspectivas: a emic, Que é o modo pelo Qual os seres humanos expressam suas visões de mundo, significados, atitudes de uma cultura particular; e a ethics, Que se constitui na interpretação ou entendimento dos significados e experiências dos seres humanos, numa visão mais universal a respeito de enfermagem, cuidado, saúde. Portanto, uma perspectiva emic é utilizada como linha de base de conhecimento, necessária para contrastar as descobertas com os pontos de vista etic, na análise dos dados obtidos: "Esta descoberta de como as pessoas sabem, vêem e vivenciam o mundo ou experiências de vida em especial, requer considerável paciência, tempo, mente aberta e estratégias de pesquisa"(4).

A etnoenfermagem é utilizada para enfocar o contexto cultural e de cuidados à saúde de uma cultura específica, com suas peculiaridades, forma, padrões, comportamentos, expressões e considerações frente ao processo de saúde e doença, podendo proporcionar diversos benefícios para os trabalhadores da saúde, e, principalmente, para os usuários por eles assistidos. Os trabalhadores, desse modo, podem obter uma visão mais ampla dos aspectos culturais Que predominam neste contexto e este conhecimento serve como base para a tomada de decisões e ações do cuidado, de modo humanizado e com Qualidade.

Assim, a etnoenfermagem como metodologia de peseuisa foi escolhida com o propósito de conhecer e compreender como ocorre o processo de construção moral dos trabalhadores de saúde para uma atuação ética pautada na autonomia, revelando possíveis interrelações e sua importância para a compreensão e direcionamento das ações. Considerando a relevância e pertinência da etnoenfermagem para a apreensão de fenômenos, em especial, o processo de construção moral dos trabalhadores de enfermagem e com a intenção de compreender os seres humanos e as relações entre si e o ambiente, baseando-se "na premissa de Que os conhecimentos sobre os indivíduos só são possíveis com a descrição da experiência humana, tal como ela é vivida e tal como ela é definida por seus próprios atores"(5) ${ }^{(5)}$ tem-se como objetivo descrever passo a passo como ocorreu o processo metodológico de implementação de uma etnoenfermagem, a partir do proposto por Leininger.

\section{METODOLOGIA}

\section{O Processo de Implementação da Etnoenfermagem}

A proposta contemplou todos os aspectos éticos preconizados pela resolução CNS - 196/96 ${ }^{(6)}$. O estudo, após aprovação pelo Comitê de Ética da Universidade Federal de Santa Catarina (Projeto No. 269/ 2005), foi desenvolvido junto aos trabalhadores de saúde da Unidade de Terapia Intensiva (UTI) do Hospital Universitário Dr. Miguel Riet Corrêa Jr. da Fundação Universidade Federal do Rio Grande (HU/ FURG), por ser o local no eual a pesquisadora já desenvolveu atividades como enfermeira assistencial e vem desenvolvendo atividades como docente e de onde emergiram, prioritariamente, suas inфuietações. Levou-se em consideração Que ter um conhecimento prévio das características destes trabalhadores favoreceria a pesquisa, na perspectiva da etnoenfermagem, desde Que não contaminado por visões predeterminadas sobre os dados obtidos ${ }^{(3)}$.

A construção de uma proposta calcada na Etnoenfermagem exigiu a reinserção da pesQuisadora no contexto dessa UTI, possibilitando estar junto aos trabalhadores para observá-los e ouvilos no desenvolvimento de suas ações; atentar para as manifestações do exercício e do não exercício da sua autonomia; observar e participar do seu fazer; entrevistá-los, procurando aprofundar aspectos detectados na observação; discutir e analisar as percepções individuais, os valores, crenças, vivências de cada um deles, bem como as do coletivo, no seu processo de construção moral.

Como metodologia de peseuisa, a etnoenfermagem compreende Quatro fases de observação, uma fase de entrevista e Quatro fases de análise dos dados, contemplando critérios específicos e congruentes com o paradigma Qualitativo ${ }^{(4)}$. Apesar desta forma de divisão, estas fases não são estanQues: inter-relacionam-se ,num movimento de ida e vinda de modo imbricado. Assim, as técnicas de observação e entrevista e a análise dos dados ocorreram concomitantemente, a partir do início do processo de coleta de dados até o seu final.

As observações iniciaram-se em setembro de 2005, perfazendo 24 turnos de trabalho, num total de 83 horas; o período de permanência variou de 2 a 6 horas de observação. Inicialmente, realizou-se um contato com os trabalhadores de UTI, durante o próprio horário de suas atividades, explicando os objetivos e a metodologia do estudo, convidando-os à participação, solicitando seu livre consentimento e estimulando seu interesse em relação à proposta.

A primeira fase da observação (observação não participante) é aquela em que "o pesquisador enfoca a atividade de fazer as observações próximas e ou distantes”(3). Nesta fase, é importante observar e ouvir os sujeitos, obtendo uma visão ampla para detalhar as observações, em especial, o contexto cultural. É essencial fazer 
observações detalhadas e documentadas antes de interagir com os sujeitos, de modo a não influenciar a situação( ${ }^{(3)}$.

Nesta primeira fase de observação, a pesQuisadora adentrou no mundo dos trabalhadores, obtendo uma visão ampla do contexto cultural da UTI, aproveitando esta etapa para, mais próxima dos trabalhadores, colocar-se disponível para ouvi-los, procurando conhecer melhor sua percepção sobre a realidade. O fato de ser conhecida pela maioria dos informantes pode ter contribuído e propiciado Que esse momento inicial se tornasse acolhedor e descontraído.

As observações iniciais aconteceram na área central da UTI, nos diversos turnos e horários de trabalho e, também, no espaço reservado para o "round". O "round" é um espaço em Que os trabalhadores da saúde da UTI, acadêmicos de enfermagem e da medicina e, também, médicos assistentes que fazem parte do "staff" traçam um perfil de cada usuário internado na UTI, registrando dados relevantes, tais como valores gasométricos, valores de outros exames realizados, diagnósticos, antibióticos utilizados, atualização e revisão de prescrição médica e tomada de decisões Quanto a condutas terapêuticas. Este espaço também é utilizado para a leitura e discussão de artigos científicos.

Percebeu-se, neste momento, Que os trabalhadores manifestaram-se satisfeitos em participar do estudo, bem como, pareciam sentir uma necessidade de dialogar, de expressar suas idéias frente ao contexto cultural, como Que necessitando "serem ouvidos", Que lhes fosse dispensada atenção. Aproveitou-se esta fase para observar detalhadamente o contexto. Durante as observações em si, foram registrados os aspectos mais importantes no diário de campo. Logo após, havia o necessário e suficiente afastamento para realizar os registros complementares. Em algumas situações, registrou-se inclusive a fala dos informantes.

Nesta fase, atentou-se ao fazer de todos os trabalhadores presentes no turno. O número de participantes foi se definindo espontaneamente, de acordo com a sua adesão, mediante a manifestação de seu interesse, constituindo-se de Quarenta trabalhadores: 6 enfermeiros; 8 técnicos de enfermagem; 10 auxiliares de enfermagem; 2 acadêmicas de enfermagem; 7 médicos; 2 médicos residentes; 2 estagiários de medicina; I fisioterapeuta; I técnica de nutrição e I funcionária da higienização. Observou-se o cotidiano do seu trabalho, identificando-se como os trabalhadores desempenhavam suas atividades, na relação com os usuários, na relação entre si, na relação com os familiares, na relação com a administração. Enfim, como exerciam suas ações, como transitavam entre o Que necessitava ser realizado e o Que era realizado.

A partir dessas observações, emergiram diversos Questionamentos: Quais ações de cuidado implementadas pela equipe de saúde foram desencadeadas pela enfermeira, pelo técnico de enfermagem ou pelo auxiliar de enfermagem? As ações de cuidado prestadas pelos trabalhadores decorreram de sua própria iniciativa frente ás necessidades manifestadas pelos pacientes, como a mucosa oral ressequida, o posicionamento inadequado no leito, as condições higiênicas inadeQuadas ou, apenas, por meio de uma determinação feita por outrem como, por exemplo, mediante uma prescrição médica? De modo semelhante, como o médico desencadeia o processo de cuidado com o usuário, com a família, com a equipe? Que diálogo tem estabelecido neste ambiente, com os diferentes sujeitos? Como ocorre na UTI o processo de tomada de decisão em relação à implementação de cuidados e tratamentos?

Na segunda fase da observação, "a observação continua como foco mais importante, mas alguma participação ocorre. O pesquisador começa a interagir com os sujeitos e observa suas respostas"(7). Assim, vai interagindo com eles, observando seu fazer e suas ações e reações: "Alguns informantes são acompanhados em suas atividades, de modo Que o pesquisador permaneça mais tempo com cada participante, possibilitando uma aproximação maior e uma observação detalhada”. Podem iniciar, também, as conversas informais, de modo a perceber, identificar e buscar compreender como exercem suas ações e tomadas de decisões ${ }^{(8)}$.

Nesta segunda fase da observação, a observação continuou a ser priorizada, porém, gradativamente foi havendo maior aproximação dos trabalhadores, com momentos de participação em discussões e ações, atentando-se a suas respostas e comentários. À medida Que se permanecia mais tempo na UTI, os diálogos também eram favorecidos. Os trabalhadores falaram de dilemas vivenciados no cotidiano do trabalho, aparentemente "Querendo" respostas para a sua resolução. Embora este não fosse o foco do estudo, procurou-se ouvi-los e encorajá-los para o seu enfrentamento.

Simultaneamente à fase de Coleta e Documentação dos Dados Brutos, ocorreu a primeira fase da análise dos dados. $\mathbf{O}$ processo de análise inclui o que é dito e observado, posturas, gestos, sentimentos, a compreensão de valores Que norteiam as ações dos sujeitos, reunidos para obter uma visão total do fenômeno. Procurouse estar atento para semelhanças e diferenças, incluindo "aspectos de estruturas sociais: valores políticos, familiares, sociais, econômicos, religiosos e práticas de cuidados"(3).

Esta etapa da pesquisa teve como finalidade compreender e reconhecer o conteúdo da informação colhida, facilitando a compreensão dos dados. Para tanto, fez-se necessário ler, reler, refletir sobre os achados, utilizando-se dos registros realizados no diário de campo, sendo analisados os dados relacionados com os informantes gerais. Assim, procurou-se realizar interpretações e atribuir significados, frente ao exercício ou não exercício da autonomia. A partir da organização dos dados e da compreensão da pesquisadora, identificaram-se os informantes-chave ${ }^{(3)}$.

A Seleção dos informantes-chave envolveu a identificação dos trabalhadores da UTI Que demonstraram potencial para revelar informações consistentes ao entendimento dos objetivos do estudo. Para tanto, foram considerados alguns critérios: Que, no mínimo, fosse selecionado um trabalhador da saúde de cada área e representantes de todos os turnos de trabalho, para contemplar as diferentes profissões e turnos, assim como, ter manifestado previamente uma aparente manifestação de exercício de autonomia ou da necessidade de uma ação heterônoma. Dentre eles, identificaram-se Quinze trabalhadores: 4 enfermeiros; 2 técnicos de enfermagem; 3 auxiliares; 4 médicos, I fisioterapeuta e I técnica de nutrição.

Na terceira fase da observação, "o pesquisador torna-se um participante mais ativo e a observação tende a diminuir porQue é difícil observar com freeüência todos os aspectos Que estão ocorrendo, enquanto se participa das atividades dos informantes", devendo-se manter atento à condição de observação ${ }^{(3)}$. Nesta fase, durante a realização de ações conjuntas, a pes\&uisadora tornou-se uma participante mais ativa nas ações dos trabalhadores, embora se mantendo atenta à condição de observação. Esta etapa favoreceu 
o envolvimento entre a pesquisadora e trabalhadores, o Qual permitiu não apenas apreender as visões de mundo, sentimentos, significados atribuídos e suas vivências como sujeitos, mas possibilitou, também, comprovar Que "a participação direta associada à continuidade da observação, favorece a aproximação com os sentimentos e com as experiências vividas dos informantes, além de fortalecer os vínculos e a relação de confiança"(8).

Além da interação nas mais diversas ações de cuidado, existiram momentos de discussões, com a participação da pesQuisadora juntamente à equipe interdisciplinar no "round". Diariamente, a pesquisadora era convidada a participar desses momentos. No entanto, muitas vezes, declinava do convite para observar os períodos de visita dos familiares e as relações estabelecidas pelos trabalhadores. Numa única oportunidade a pesquisadora se fez presente na sala de lanche, Quando houve um momento de descontração com os trabalhadores.

Concomitantemente à terceira fase de observação, iniciou-se a segunda fase de análise. Nesta fase da análise, os dados foram estudados para identificar as diferenças e semelhanças frente ao modo como os trabalhadores da saúde da UTI expressaram suas ações, visões de mundo, significados, valores e tomada de decisões ao desenvolver o cuidado, buscando vislumbrar como ocorre a construção moral dos trabalhadores de saúde para uma atuação pautada na autonomia.

A partir dos significados e do comportamento aparentemente predominante na cultura da UTI, de alguns dos valores Que parecem nortear as ações dos trabalhadores, de alguns dos fatores considerados para a tomada de decisão e das interpretações e valores atribuídos pela própria pesquisadora, bem como de comparações com experiências e comportamentos numa visão mais universal a respeito de cuidado e saúde, os dados começaram, a ser organizados em categorias e subcategorias, as Quais passaram a caracterizar os componentes da análise. Nesta fase, foi elaborado um roteiro de entrevista com alguns enfoQues gerais e, também, contemplando situações específicas a cada informante-chave, de acordo com observações pontuais em particular, dando-se início às entrevistas.

Desse modo, para a coleta de dados, a partir da terceira etapa do período de observação, utilizou-se a técnica de entrevista, uma vez Que permite tratar de assuntos pessoais e aprofundar aspectos observados, admitindo correções e esclarecimentos, com vistas à maior segurança e fidedignidade na coleta e análise dos $\operatorname{dados}^{(3)}$. A entrevista "carrega em si uma intimidade única Que é compartilhada entre o entrevistador e o respondente"(9), sendo Que as informações reveladas não são discutidas num Questionário, pois, muitas vezes, vêm acompanhadas de fortes emoções. Portanto, é importante Que o pesquisador favoreça este momento de intimidade, planejando a entrevista e estabelecendo um ambiente de confiança e harmonia. As estratégias de manter a atenção, sacudir a cabeça, olhar atento, aproximar-se do sujeito favorecem o seu interesse. Daí poder se considerar a entrevista como um dos métodos de coleta de dados mais importante $e^{(7)}$.

Durante a entrevista, o pesquisador pode aproximar idéias sobre o comportamento ou respostas obtidas nas observações. Assim, "estruturar Questões da entrevista ou domínios de tópico ajuda o entrevistado a saber de onde o entrevistador vem ou a situação contextual e seus significados explícitos ou implícitos"(3). É importante Que se pense como estruturar Questões, Que se esteja disponível para ouvir, demonstrando interesse, de modo a compartilhar informações específicas e gerais, sendo essencial a empatia para entrar no mundo, cultura ou situação do sujeito ${ }^{(3)}$.

Assim, adotou-se a entrevista semi-estruturada, na Qual as Questões foram formuladas para obter conhecimento e ajudar a perceber, de modo a guiar as discussões para Questões mais específicas, provocadas pelos dados já colhidos na observação, com vistas ao alcance dos objetivos do estudo, mediante o relato de vivências, situações, detalhes, exemplos e contextos específicos e gerais do entrevistado, possibilitando a interpretação de idéias, declarações, sentidos e significações ${ }^{(3)}$. As entrevistas iniciaram-se em dezembro de 2005 e encerraram-se em abril de 2006.

A maioria das entrevistas foi realizada no próprio local e horário de trabalho; combinada previamente, mediante acordo entre os informantes e a pesquisadora, durando, em média, I hora a 1 hora e 30 minutos. Alguns trabalhadores preferiram realizar a entrevista antes de seu horário de trabalho e outros, agendar em outro local, para disporem de maior traneüilidade. Reconhecendo Que cada trabalhador da saúde possui experiências e vivências diferenciadas no seu processo de construção moral para uma ação pautada na autonomia, procurou-se, durante a entrevista, buscar elementos de sua história pessoal e profissional Que reconheciam como significativos em sua construção moral. Para garantir a fidedignidade das informações, as falas foram gravadas em fitas cassetes, mediante a autorização dos participantes e, logo após, transcritas, prosseguindo-se, de imediato, o processo de análise.

Antes da realização da entrevista, como já referido, eram lidas as anotações do diário de campo, a respeito do informante Que seria entrevistado. As ações registradas foram a base dos Questionamentos, constituindo-se numa possibilidade para Que os informantes pudessem expressar seus pontos de vista, sentimentos e percepções frente ao seu modo de ser e agir. Durante o seu transcorrer, foram construindo-se novos Questionamentos, à medida Que as respostas eram obtidas, de modo a apreender as percepções e significados atribuídos pelos informantes, com vistas à validação dos dados observados anteriormente.

Assim, cada trabalhador foi entrevistado, mediante o registro de suas ações, frente ao modo como as exercia, sendo estimulado a expressar como construiu seu modo de agir, o Que pensava sobre suas atitudes; Que valores e fatores considerava para tomar decisões e agir; como transitava entre o que necessitava ser realizado e o Que era realizado; como percebia o seu fazer e o de seus colegas de trabalho e como visualizava o seu processo de construção moral e dos trabalhadores de um modo geral. Assim, foi possível enriQuecer as sub-categorias de significados na cultura da UTI, atentando-se não só às idéias, pensamentos, valores e ações individualizados, mas também procurando relacionar e comparar os dados aos de outros trabalhadores.

$\mathrm{Na}$ terceira fase de análise, os dados obtidos nas entrevistas foram analisados, comparados e organizados, concomitantemente com as sub-categorias anteriores, para descobrir padrões de comportamento e significados estruturais. Procurou-se evidenciar as temáticas mais significativas dentre as Que foram abordadas, de modo a resgatá-las e aprofundá-las, com os informantes. A devolução dos dados para a validação foi realizada mediante a apresentação das interpretações, componentes e sub-categorias para os informantes, discutindo e refletindo sobre os achados, de modo 
a evidenciar os padrões recorrentes, a consistência e credibilidade das informações, compondo-se as categorias.

O total de participantes foi determinado pela saturação dos dados, Quando a coleta não produziu novas informações, ou seja, Quando os dados novos produziram informações redundantes ${ }^{(2)}$. Portanto, a redundância é um termo intimamente ligado à saturação, no Que se refere à tendência de obter dados similares, repetidos ou duplicados, com idéias, significados, descrições e outras expressões humanas de informantes ou do contexto do estudo. É "a evidência de ter obtido tudo o que pode ser conhecido ou compreendido por um fenômeno sob estudo" (4).

$\mathrm{Na}$ Quarta fase da observação, após a realização das entrevistas, o pesquisador faz observações reflexivas. Isto,"significa "olhar para trás' reflexivamente sobre o Que acontece e recapturar a situação e o processo total do Que aconteceu", avaliando as informações encontradas $^{(3)}$. Nesta fase, a pesquisadora avaliou a sua própria influência, o aprendizado para saber ouvir e observar, obtendo uma idéia apurada e mais honesta sobre os acontecimentos, revendo situações, direcionando um reolhar e reavaliando os dados encontrados, procurando analisar o comportamento e ações globais dos informantes como: postura, gestos, mímicas, mudanças no tom da voz, sorriso, modos de agir, percepções de como os trabalhadores agem frente às situações vivenciadas no contexto de trabalho; o Que é dito ou não dito, o Que é feito ou não é feito frente às situações, Quais as reações diante das ações de outros; a expressão de sentimentos, impressões e reflexões.

A Quarta fase de análise constitui-se da síntese dos dados, da abstração de categorias e formulações teóricas. Esta fase exigiu síntese de pensamento, abstração e descoberta de temáticas importantes, com análise criativa de dados das fases anteriores. Refletiu-se sobre as informações, comparando-as com achados daliteratura, possíveis formulações teóricas e recomendações, sem a pretensão de esgotar a temática.

\section{CONSIDERAÇÕES FINAIS}

Um caminho metodológico delineado a partir da proposta de etnoenfermagem desenvolvido no contexto dos trabalhadores de uma UTI, mostrou-se de grande valia para o alcance dos objetivos do estudo. O desenvolvimento de pesquisa a partir da proposta de Leininger, de Etnoenfermagem, pode constituir-se numa estratégia a ser utilizada por outros pesquisadores, insatisfeitos com as dificuldades vivenciadas no contexto cultural de trabalho, desejosos de refleti-lo e de buscar alternativas.

Neste estudo, utilizou-se a abordagem etnográfica com uma apropriação peculiar, uma vez Que se buscou compreender a realidade cultural dos trabalhadores da saúde, os valores Que norteiam suas ações e os fatores levados em consideração no contexto do dia-a-dia de trabalho, com o desafio de apresentar como os trabalhadores da saúde têm interiorizado valores, modos de ser e de fazer, construídos culturalmente, o Que propicia a sua construção moral, o exercício da autonomia, favorecendo o cuidado a saúde.

Considera-se, também, Que o conhecimento produzido poderá contribuir para a formação do enfermeiro e dos trabalhadores da saúde de um modo geral, proporcionando novas competências no cuidar, bem como avançando e trazendo subsídios e contribuições para a teoria da Diversidade e Universalidade do Cuidado Transcultural. Tal contribuição justifica-se pois não houve apenas a preocupação com o cuidado de enfermagem cultural do indivíduo a ser assistido, mas, sim, o desafio de buscar conhecimentos Que, possivelmente, favorecerão também a prática dos trabalhadores da saúde, desenvolvendo a enfermagem como ciência e proporcionando novos caminhos para o cuidado a saúde, o exercício da profissão, a ética, complementando a Teoria de Leininger.

\section{REFERÊNCIAS}

I. Leininger MM. Culture care diversity and universality: a theory of nursing. New York: National League for Nursing Press; 1991.

2. Oriá MO, Ximenes LB, Alves MDS. Madeleine Leininger e a teoria da diversidade e universalidade do cuidado cultural - um resgate histórico. Rio de Janeiro; 2006. [citado em 0I jan 2006]. Disponível em: http://www.uff.br/nepae/

3. Leininger M. Etnography and Ethnonursing: models and modes of Qualitative data analysis. Orlando: Grune \& Stratton; 1985.

4. Leininger M. Ethnomethods: the philosophic and epistemic bases to explicate transcultural nursing know legde. I Transcultural Nurs 1990; I(2): 40-51.

5. Polit DF, Hungler BP. Fundamentos de pesquisa em enfermagem. Porto Alegre: Artes Médicas; 1995.
6. Ministério da Saúde (BR). Conselho Nacional de Saúde. Resolução No 196/96. Dispõe sobre pesquisa envolvendo seres humanos. Brasília: Ministério da Saúde; 1996.

7. Rosa GN. Dilemas éticos no mundo do cuidar de um serviço de emergência [dissertação]. Porto Alegre (RS): Universidade Federal do Rio Grande do Sul; 2001.

8. Rosa NG, Lucena AF, Crossetti MGO. Etnografia e etnoenfermagem: métodos de pesquisa em enfermagem. Rev Gaúcha Enferm 2003; 24(1): 14-22.

9. Sorrel IM, Redmond GM. Interviewws in Qualitative nursing research: differing approaches for ethnographic and phenomenological studies. I Adv Nurs 1995; 21 (6): 1117 I 122. 